\title{
D. Fr. Timóteo do Sacramento: administração diocesana, reforma de costumes e conflitos na Amazônia Portuguesa (1697-1713) ${ }^{1}$
}

\author{
D. Fr. Timóteo do Sacramento: Diocesan Administration, Reform \\ of Customs and Conflict in the portuguese Amazon (1697-1713)
}

Pollyanna Gouveia Mendonça Muniz

\section{Resumo}

São raros os estudos sobre o episcopado na Amazônia Portuguesa do século XVII. Em 1697, Fr. Timóteo do Sacramento foi o segundo bispo a assumir a diocese do Maranhão, território amplo que englobava as capitanias do Maranhão e do Grão-Pará. O objetivo do artigo é analisar a administração diocesana e os conflitos que marcaram o governo desse prelado. Objetivando corrigir os desviantes, ele determinou prisões e excomungou várias pessoas nas cidades de São Luís e Belém. Pelo cruzamento de diferentes acervos documentais, alguns deles inéditos, é possível acompanhar como esse antístite atuou no governo de sua diocese. Para demonstrar a complexidade da introdução da jurisdição episcopal, analisaremos os conflitos do bispo com autoridades eclesiásticas, com membros do clero regular e com autoridades do reino.

Palavras-chave: administração eclesiástica; bispado; Maranhão.

\section{Abstract}

Studies on the episcopate in the 17th century Portuguese Amazon are rare. In 1697, Fr. Timóteo do Sacramento was the second bishop to assume the diocese of Maranhão, a wide territory that encompassed the captaincies of Maranhão and Grão-Pará. The purpose of the article is to analyze the diocesan administration and the conflicts that marked the government of this prelate. To correct the deviations, he determined arrests and excommunicated several people in the cities of São Luís and Belém. By crossing different documents, some of them unpublished, it is possible to follow how this bishop acted in the government of his territory. To demonstrate the complexity of the introduction of episcopal jurisdiction, we will analyze the conflicts he has had with ecclesiastical authorities, with members of the regular clergy and with officials of the kingdom.

Keywords: ecclesiastical administration; bishopric; Maranhão.

\footnotetext{
* Universidade Federal do Maranhão (UFMA), São Luís, MA, Brasil. pollyannagm@yahoo.com.br $<$ https://orcid.org/0000-0002-2528-1748>
} 
D. Fr. Timóteo do Sacramento chegou ao seu território episcopal, o bispado do Maranhão, em 1697. As dimensões do bispado que assumiu eram imensas, o que era comum aos bispados ultramarinos. Estendia-se desde o Cabo do Norte e englobava as capitanias do Maranhão e do Grão-Pará (Silva, 1922, p. 68). Era a Amazônia Portuguesa. Apesar de a documentação não mencionar o termo, tem sido constante o interesse pela região e, especialmente, pela historicização do seu passado colonial. Uma recente historiografia tem avançado nas discussões sobre o papel fundamental dessa região que estava, pós-União Ibérica, no "meio", entre as Índias de Castela e o Estado do Brasil e, por conta dessa configuração, foi importante para demarcar a soberania da monarquia portuguesa no território (Corrêa, 2011). Denominado ainda de "Atlântico equatorial" (Chambouleyron, 2006), esse território deve, segundo essas interpretações, ser retirado da lógica interpretativa nacional e clássica, que confere importância principal ao norte do Atlântico Sul, para ser visto como integrante do sul do Atlântico Norte, pois as rotas comerciais equatoriais eram as mesmas dos domínios espanhóis (Cardoso, 2012).

A região, pois, era estratégica e a implantação do bispado em 1677 deveria contribuir sobremaneira para o alargamento do poder da monarquia portuguesa na região. Sobre a criação das dioceses amazônicas (Maranhão e Pará), Evergton Souza afirma ser um bom exemplo de quando a Coroa foi a principal responsável pela estruturação da malha diocesana. Ele destaca que as preocupações políticas devem ter pesado na decisão régia de solicitar a criação das novas dioceses. Isso porque era preciso expandir as fronteiras dos domínios portugueses e efetuar uma melhor gestão das tensões existentes entre missionários e colonos por causa da mão de obra indígena (Souza, 2014, p. 183-184).

A chegada das ordens regulares foi o primeiro passo da entrada do catolicismo na região. Os franciscanos da Província de Santo Antônio foram os primeiros a chegar ao mundo amazônico. Depois deles vieram os missionários da Companhia de Jesus e, com o passar dos anos, chegaram as ordem dos Carmelitas e dos Mercedários. Outras províncias dos franciscanos também aportaram em solo amazônico, como os Capuchos da Piedade e, por fim, os Frades da Conceição da Beira e Minho (Carvalho Júnior, 2013, p. 25). Essas ordens regulares respondiam, entretanto, aos superiores de suas casas e, claro, ao papa. D. Fr. Timóteo do Sacramento foi o segundo bispo ${ }^{2}$ a residir no bispado do Maranhão e o último a ter jurisdição no amplo território que englobava o Grão-Pará e o restante dos espaços que estamos denominando de Amazônia Portuguesa.

Pensar a prelazia desse prelado nessas proporções é demonstrar a impor- 
tância da instalação de um bispado naquele espaço e, principalmente, demonstrar o interesse da Igreja, sob o padroado, ${ }^{3}$ em alcançar territórios antes marcados prioritariamente pela presença do clero regular. Submetidos diretamente ao poder real, os bispos poderiam ser agentes diretos da monarquia naquela região. O território só foi desmembrado em dois quando o papa Clemente XI criou o bispado do Pará, em 1719, e o limite entre as duas dioceses se estendeu até o rio Gurupi (Meireles, 1977, p. 116). Interessam-nos, pois, os anos iniciais da introdução da jurisdição ordinária no território do Estado do Maranhão e Grão-Pará, ou seja, da Amazônia Portuguesa, e como pôde a Igreja atuar na construção e organização de sua diocese naquela região.

A análise da trajetória de D. Fr. Timóteo do Sacramento no bispado do Maranhão foi feita tanto por seus contemporâneos como por estudiosos posteriores. Berredo (1988 [1749]), Bettendorf (1910 [1698]), Fr. Francisco de Nossa Senhora dos Prazeres (1891), César Marques (2008 [1870]), D. Felipe Conduru Pacheco (1969), Mario Meirelles (1977), D. Francisco de Paula e Silva (1922) e Maria Madalena Larcher (1997) dedicaram páginas de suas obras à atuação desse bispo. Tais análises são marcadas por duas características principais. A primeira, a alegação comum de falta de fontes para analisar o século XVII, especialmente no que diz respeito ao governo dos bispos. A segunda, as tentativas recorrentes de produzir juízos de valor sobre seu episcopado.

Sobre a primeira característica, segue a constatação inicial: há fontes. O que esses primeiros trabalhos consultaram reduz-se basicamente às fontes do Arquivo Histórico Ultramarino das capitanias do Pará e do Maranhão, onde há ao menos 21 menções ao antístite em variadas situações. Este artigo pretende chamar atenção para dois acervos praticamente inéditos: a documentação do senado da câmara de São Luis e os livros de provisão do bispado do Maranhão. ${ }^{4}$

A documentação da câmara do Maranhão tem servido de base para analisar marcadamente a administração e política colonial (Correa, 2011; Ximendes, 2010), mas a nossa proposta é utilizá-la para observar como as autoridades camarárias descreveram a atuação de membros da igreja, notadamente o bispo D. Fr. Timóteo. Trata-se, pois, de acervo riquíssimo e que permite analisar vários aspectos da vida colonial do Maranhão. Nesses documentos é possível perceber de forma privilegiada os acontecimentos do período da permanência do bispo no Maranhão até 1700, quando ele partiu para Lisboa. Por ela é possível conhecer as missivas enviadas não apenas ao rei, mas entre as autoridades camarárias e o governador, o ouvidor-geral e, um dado que é novo, entre a câmara e as ordens regulares.

No livro de provisões do bispado é possível conhecer as provisões passa- 
das pelo bispo D. Fr. Timóteo que demonstram sua preocupação com a administração do vasto território que abrangia o antigo Estado Colonial do Maranhão e Grão-Pará, bem como algumas de suas pastorais e a transcrição de algumas cartas importantes sobre conflitos com as demais instâncias de poder local. É o livro em que se registrava o cotidiano burocrático do bispado, os personagens que assumiam as funções e quais eram as principais preocupações administrativas do prelado. Por ele, será possível traçar aspectos inéditos de sua administração diocesana e da montagem da máquina burocrática da justiça eclesiástica.

O segundo motivo da dificuldade de reflexão sobre o personagem é, como disse, as tentativas de absolvê-lo ou de condená-lo. Desde as obras contemporâneas ao tempo em que ele viveu até as posteriores, o que há é um esforço em defender as autoridades reais e condenar o antístite como um grande articulador de conflitos. O objetivo do estudo aqui apresentado é outro. Pretende-se ultrapassar as interpretações generalistas e pouco problematizadoras acerca desse personagem que foram glosadas e incorporadas acriticamente pela historiografia do século XX. Só com uma análise metodológica mais apurada e usando fontes variadas, como as que apresentaremos, é que se pode observar melhor sua trajetória.

\section{A administração diocesana na Amazônia Portuguesa}

Maria Madalena Larcher afirma que D. Fr. Timóteo nasceu em Lisboa em 5 de fevereiro de 1653 e professou na Ordem dos Eremitas de São Paulo, da Congregação Serra d'Ossa, no Convento do Santo Sacramento daquela cidade, em julho 1670. Confirmado como bispo de São Tomé e Príncipe em 2 de janeiro de 1693, seria nomeado bispo do Maranhão pelo rei Pedro em 1695, nomeação confirmada pela bula papal de Inocêncio XII, Gratiae divinum praemium, datada de 17 de dezembro de $1696 .^{5}$

Antes de partir para seu bispado, D. Fr. Timóteo do Sacramento alegou estar em condições adversas. Não tinha como custear sua travessia ao Maranhão e muito menos tinha assumido o bispado de São Tomé, anos antes, pelo que reclamava nunca ter recebido as côngruas. Peticionou ao rei D. Pedro II pedindo "em consideração das rezõens referidas lhe faça mercê mardarlhe dar quatro centos mil réis por empréstimo a conta de sua congrua para com elles se poder aprestar visto a brevidade de que depende a sua partida" (Arquivo Histórico Ultramarino (doravante, AHU), Capitania do Maranhão (doravante MA), doc. 940). O parecer foi favorável "tomando à Rezolução da tripartita que a muitos bispos ultramarinos se concederão as ajudas dos seus aprestos, e 
que este Perlado he notoriamente pobre". Assim se fazia "digno de que Vossa Majestade use de sua grandeza com elle, e ao mesmo que se observou com os mais". Ordenou então que "ao Provedor da Fazenda, que o frette de o conduzirem com seu fatto, e famillia para aquele Estado se pague por conta da Fazenda Real" (AHU, MA, doc. 954).

Em 1697 pediu também que sua Majestade lhe concedesse uma outra benesse: uma aldeia de índios. Na sua petição informa que ao "seu antecessor Dom Frey Gregório dos Anjos foi vossa magestade servido dar hua’ aldea de índios para o serviço da sua pessoa" além de "casas para morar pagas a custa da fazenda real de vossa majestade, pela qual rezão lhe assiste a elle Suplicante hua' justa esperança de que vossa majestade lhe faça a mesma mercê" (AHU, MA, doc. 941). O parecer do Conselho Ultramarino, seguido depois pelo rei, considerou justo o pedido de casas para morar à custa da Fazenda Real, "porém emquanto a aldea de indios que pede para seu serviço que não tem lugar o deferir pois se reconhece neste caso que este prelado tem da sua côngrua com que possa pagar a quem lhe houver de assistir" (Idem).

A presença dos indígenas em grande quantidade era uma das características do território assumido por D. Fr. Timóteo. A disputa por essa mão de obra tinha, anos antes, desembocado num grande movimento revoltoso intitulado Revolta de Beckman ${ }^{6}$ (Caetano, 2008; Liberman, 1983) que, entre outras consequências, determinou a expulsão dos jesuítas do Maranhão. Mesmo passados já alguns anos do conflito, a disputa pela mão de obra dos índios era assunto sempre em voga na Amazônia Portuguesa. O tribunal da Junta das Missões (Ferreira, 2017), criado para solucionar questões envolvendo os nativos, tinha o bispo como um dos seus deputados. O importante a ressaltar é que a coroa já entendia que a concessão de uma aldeia inteira ao prelado poderia gerar muitos conflitos com as autoridades locais, com o clero regular já instalado e com os colonos que dependiam dessa mão de obra para suas plantações.

No que tange à administração de sua diocese, sentiu logo que os seus pedidos não eram a prioridade que o rei deveria ter na região. O bispo solicitou que se nomeassem dignidades para assistirem com ele nos ofícios episcopais. Dado relevante é a explicação da negativa do pedido, alegando-se que faltavam recursos. Além disso, na interpretação dos pareceristas do Conselho Ultramarino havia outros setores mais importantes a pagar naquelas terras de conquista. Alegavam que a receita não chegava "para o pagamento dos filhos da folha, de que rezulta ficarem devendo a mayor parte dos ordenados aos que serviam a vossa majestade naquela conquista, experimentando esta falta a infantaria". Relatavam as queixas do governador por "estarem devendoselhe dous anos de 
seus soldados". Deliberaram, finalmente que "nos termos presentes não está capaz para concorrer para o pagamento destas dignidades, que melhorandosse o rendimento dela, então haverá lugar para a nomeação delas"(AHU, MA, doc. 954).

No Livro de Provisões constam 18 provisões passadas pelo bispo e sete cartas pastorais. No ano de sua chegada, 1697, tratou de nomear vigário-geral, escrivão do auditório e da câmara, ${ }^{7}$ entre outros. O mais relevante a destacar é a provisão de vigário da vara forâneo de 1698 passada ao padre Francisco Tavares de Macedo da capitania do Pará. Pela provisão - que até o momento é o mais antigo documento completo sobre esse ofício localizado para a América Portuguesa - é possível conhecer as atribuições dessa função: "poder para suspender pregadores e confessores, poder tirar e inquirir autos de cazamento e não tendo impedimentos sentencialos na forma do sagrado Concilio Tridentino". Poderia proceder contra os párocos que fossem omissos e delinquentes. E, finalmente, exemplificando claramente a jurisdição delegada pelo bispo: deu poder a por censuras em defesa da unidade da Igreja e "para obrar tudo aquilo que for do serviço de Deos que por causa da distancia não podemos acudir, com devida jurisdição a tudo que for demandas quer civeis, quer crimes e querelas e quaisquer causas litigiosas" (Arquivo Público do Estado do Maranhão (doravante, Apem), Acervo Eclesiástico, Livro de Provisões, n. 81, s. n).

$\mathrm{O}$ dado mais relevante da provisão, entretanto, é sua parte final. Nela o bispo mandava "aos moradores da capitania do Pará e suas annexas assim eccleziásticas como seculares reconheçam, respeitem e obedeçam como seo Prelado" (Apem, Livro de Provisões, n. 81, s. n). Trata-se, portanto, de uma jurisdição alargadíssima a ponto de determinar que o obedecessem como se fosse seu prelado. Eram as concessões e adaptações feitas pela Igreja no espaço colonial muito antes da publicação das Constituições Primeiras do Arcebispado da Bahia, de 1707. A tentativa de D. Fr. Timóteo era de melhor atender aos habitantes do Pará, tão distantes da sede do bispado em São Luís. Belém era lugar de morada das autoridades seculares. Um vigário da vara forâneo com tantos poderes era seu representante direto no Pará, alguém de sua confiança para administrar a justiça eclesiástica naquelas partes.

Na documentação do Arquivo Histórico Ultramarino é possível observar, nas entrelinhas, como na prática essa jurisdição alargada foi se consolidando em poucos anos e ainda no governo diocesano de D. Fr. Timóteo do Sacramento. O denominado "vigário-geral do Pará", padre Antonio Maciel Parente, recebeu, em 1705, denúncia feita por Manuel de Oliveira Pantoja contra o padre Francisco Soares de Albergaria, afirmando que ele foi expulso da Com- 
panhia de Jesus porque era "hu' clérigo mal dizente emfamador das honras e vidas alheias, que lhe não escapa Religioso, ministro secular, viúva, casada ou Donzela fazendolhe sátiras em versos defamatorios..." (AHU, PA, doc. 411). O interessante é o detalhe de que Pantoja diz já ter denunciado o padre Manuel no tribunal episcopal anos antes. Ou seja, esclarece que havia instalada a instância do juízo eclesiástico em Belém antes de 1705, o que confirma a especificidade da provisão de vigário da vara forâneo de fins do século XVII, anteriormente mencionada. Não se tratava de um vigário da vara comum. O vigário da vara forâneo, anos depois denominado vigário-geral, era já o juiz de um tribunal eclesiástico em funcionamento no Pará.

As provisões passadas por D. Fr. Timóteo também demonstram a constante falta de oficiais para exercerem as funções no tribunal episcopal. $\mathrm{Na}$ falta de pessoas eclesiásticas para assumir as funções de escrivão do auditório e da câmara eclesiástica, por exemplo, teve de nomear um leigo para a função, Eugenio Ferreira de Castro, homem casado e morador de São Luís que, segundo o bispo, parecia reunir as condições necessárias para o cargo. Quase todos os providos acumularam duas ou mais funções. Em 1700, por exemplo, o padre Antonio da Cruz Pinheiro assumiu as funções de promotor, inquiridor e contador do juízo eclesiástico. Nesse mesmo ano, o bispo ausentou-se para o reino e deixou em seu lugar três governadores do bispado, os padres José Goncalves Gularte, Andre Lopes Coelho e Inácio Rodrigues de Távora.

É importante demonstrar que mesmo tendo se ausentado de sua diocese naquele ano e permanecido em Portugal até seu falecimento, em $1713,{ }^{8} \mathrm{D}$. Fr. Timóteo demonstrava tentar controlar as nomeações de funções no seu distante bispado. Em 1705 passou provisão de visitador ao padre Inacio Rodrigues de Távora com obrigação de visitar o bispado, aos moldes do Concílio Tridentino, todos os anos na sua ausência. Preocupou-se, entretanto, em garantir que as eventuais apelações que fossem impetradas no seu juízo eclesiástico fossem enviadas para Lisboa para que ele deliberasse a resolução final. É de 1711 sua última provisão registrada no livro. Nomeou o padre Leandro Matos Quental como pároco da vila de Vigia no Pará, uma das ocupações mais antigas daquele território e possessão jesuítica desde a colonização da região. Após sua morte, o cabido de Lisboa passou a enviar as provisões de vigário-geral e de governador do bispado à diocese do Maranhão. Essas eram as autoridades que nomeavam o vigário forâneo das terras do Pará até a criação da diocese de Belém em 1719. 


\section{CONFlitos COM OS AGENTES DO REI}

A chegada do antístite ao seu território episcopal movimentou a todos, especialmente os oficiais seculares. O senado da câmara do Maranhão mandou cartas às autoridades contando os detalhes em 2 de junho de 1697. O primeiro a ser informado, o rei, foi imediatamente saudado pela "grandeza e benignidade de vossa magestade em tudo zellozo de nosso bem foy servido enviarnos a educação espiritual de nossas almas com a vinda do bispo que chegou em bom sucesso e fica já em sua posse" (Apem, Copiador de Cartas da Câmara, Livro 28, fl. 48v). Escreveram também ao governador Antonio de Albuquerque Coelho que estava no Pará dando notícia que "foi Deus servido trazernos o sr. bispo Fr. Timoteo do Sacramento que foi recebido nesta cidade o modo que nos foi possível” (Idem, fl. 49).

Para o ouvidor-geral, Mateus Dias da Costa, também no Pará, foram mais detalhados nas expectativas e também preocupações com a chegada do prelado. Disseram na missiva que "permitta Deos trazello para que nos melhore a sorte no espiritual de nossas almas, melhor do que temos experimentado no temporal de nossos infortúnios”. Pediram ainda a presença das autoridades reais em São Luis "para com a presença de ambos nos vermos mais assegurados de algumas perturbaçõis que sempre estas inquietações em quando falta o recurço da assistência dos majores" (Idem, fl. 52v). Nota-se a preocupação por o governador e o ouvidor estarem vivendo na capitania do Pará. Com a chegada de D. Timóteo em São Luís, a câmara já imaginava os eventuais conflitos e disputas de poderes. São Luís, a sede do bispado, e Belém, onde viviam os membros do governo secular, eram as cidades mais importantes da Amazônia Portuguesa naquele momento. Jurisdição espiritual e jurisdição secular separadas por léguas incomodavam sobremaneira o senado da câmara de São Luís.

Nem se passara um ano da chegada e, em 16 de maio de 1698, o tom da carta já era de queixa. O bispo tinha realizado visita pastoral e por culpa de concubinatos muitos foram presos. Para o rei, a carta da câmara foi mais detalhada. Contaram que

no mes de novembro de 97 principiou o bispo deste Estado a vizita geral e correção dos maos costumes, em a qual procedeo absolutamente deixando de observar as disposiçõis do direito canonico, Concilio Tridentino e direção das leis de vossa magestade, procedendo em tudo violentamente, porq saindo culpados algumas pessoas em a dita vizita no crime de concubinato, faltando lhe com as tres admoestaçois, as prendeu logo, condenou em quantias de dinheiro e degradou 
sem guardar privilégio e homenagem a alguns dos reos, sendo cidadãos desta cidade e da governança della, porq as prendeo na cadeia pública do aljube, e não só nisto se houve com excesso, mas taobem em fazer algumas prizoes absolutas; e por não admitir livramentos fez a todos os autos sumários de sinco dias sem dar nomes de testemunhas, nem asseitar apelaçõis e agravos valendose ainda da ajuda de braço secular para as ditas prizõis de cujas vexaçõis e contrario o costume se queixa este povo e a nós pareceu informar ao governador geral do Estado a capitania do Pará onde residia com o ouvidor geral no serviço de sua majestade, o qual sem demora enviou para que como juiz dos feitos da coroa desagravasse os que se achavam violentados e agravados, a que acresceu tambem verem a maior parte dos reos publicados os seus crimes e condenaçois por uma pastoral do púlpito da sé desta cidade para cujo effeito mandou o dito prelado em hu' dia santo convocar o povo debaixo de pena de excomunhão que cauzou a todos notável pejo e escandalo. (Apem, Copiador de Cartas da Câmara, Livro 28, fl. 55)

O governador enviou o ouvidor Mateus Dias da Costa para resolver os conflitos. Ele mandou soltar os presos e o bispo o excomungou juntamente com os adjuntos da coroa. Estes revidaram e decretaram as temporalidades contra o bispo. O vigário-geral excomungou o capitão-mor que tinha interditado a morada do bispo. O prelado, entretanto, rompeu "o cordão de infantaria com duas quartinhas nas mãos a emchellas de agoa a huma das fontes dessa cidade contra o seu decoro". Logo o juiz da coroa "porlhe travessas nas portas do palácio episcopal para assim haver de o obrigar a levantar as censuras, o que logo teve efeito" (Apem, Copiador de Cartas da Câmara, Livro 28, fl. 55). Terminam a missiva pedindo ao rei que "seja advertido o dito bispo de como se hade aver em administrar justiça, o que surtirá effeito observando elle o direito canónico e as leis do reino" (Idem). Em 1o de julho do mesmo ano, a câmara remeteu nova carta ao governador informando que o bispo tinha viajado para a fazenda dos jesuítas e deixado o governo das almas do seu bispado.

A documentação do Arquivo Histórico Ultramarino demonstra que a questão chegou a outro patamar. Uma carta do próprio ouvidor acusava D. Fr. Timóteo de requerer "a curia de Roma sem ordem de vossa majestade" (AHU, Capitania do Maranhão, doc. 972). O bispo pretendia envolver Roma no assunto e, para isso, enviou um procurador ao reino. Tratava-se de um clérigo regular, frei Mateus de Siqueira de Queiroz, que era acusado de sair de seu convento sem autorização de seu superior. Ele é descrito como "hu' fradinho rapaz, indiscreto, inadvertido, imprudente e, sobretudo, muito atrevido" que 
tinha interditado igrejas no Pará e excomungado quem o tentasse proibir de ir a Roma. O parecer do Conselho Ultramarino defende o direito do rei sob padroado e reclama que o bispo não devia mandar ninguém à curia romana sem ordem do rei (Idem, doc. 972).

Em fevereiro de 1699, o reitor da companhia de Jesus foi informado pela câmara que o monarca ainda não tinha respondido à contenda de meses antes envolvendo o bispo, mas que ele tinha publicado nova pastoral com proibições diversas. Assim, informavam que se moveriam "como cabeças da republica e de seo governo no politico a acodir ao socego" da cidade (Apem, Copiador de Cartas da Câmara de São Luís, Livro 28, fl. 62). Acusando os regulares de cumplicidade com o bispo, a câmara pediu enfaticamente "aos mais religiosos padres queiram socegar e por fim neste negocio" até que o rei lhes respondesse (Idem, fl. 62v).

Neste ponto, a documentação da nunciatura examinada por D. Felipe Condurú Pacheco ajuda a esclarecer ainda mais os acontecimentos. Roma interessou-se pelo que se passou no bispado do Maranhão. Desde 1698, o abade Pasqui relatava que o bispo do Maranhão recebera insultos dos oficiais seculares. Dizia que sua dignidade episcopal e sua imunidade tinham sido desrespeitadas, o que o cardeal Spada - secretário de Estado do papa - respondeu com um pedido de punição desses oficiais ao rei (Apud Pacheco, 1975, códice 161, fl. 179 e 210, fl. 39, p. 11.). Este, por sua vez, mandou que a causa fosse submetida ao Tribunal do Paço, que escreveu ao bispo que observasse os cânones e o Concílio de Trento. ${ }^{9}$ Ao ouvidor determinou que "desse satisfação conveniente ao bispo e não interferisse mais nas suas causas", pois "contra os prelados não podem proceder juízes seculares, sem antes informar o rei, especialmente nas conquistas ultramarinas" (Idem, códice 56, fl. 113, p. 12).

Julgando as medidas insuficientes, em 1699, o núncio apostólico escreveu ao cardeal secretário de Estado. Pediu que os culpados fossem punidos com mais rigor pelo rei. A carta do monarca sobre o assunto não foi registrada entre as missivas do Arquivo Histórico Ultramarino nem nos documentos da câmara, mas foi copiada na íntegra no livro de provisões do bispado do Maranhão. Nela consta que o ouvidor e demais ministros da coroa usaram "com o bispo termos indecorosos e escandalozissimos", pelo que sua majestade mandou passar "uma muito áspera repreensão por haver censurado o bispo" afirmando que "nunca se devia proceder por meios tam ásperos contra qualquer sacerdote quanto mais contra hum bispo sagrado porque nem a ley das temporalidades chegava a tanto" (APEM, Livro de Provisões, n. 81, fl. 64).

As desavenças extrapolaram, como vimos, a visita pastoral de 1697. Soma- 
das a essas, havia ainda queixas de que o bispo mandava "ordenar soldados e outras gentes de infectas gerações pela esmola de sincoenta athe duzentos mil” (AHU, Capitania do Maranhão, doc. 1017). A dificuldade em encontrar clérigos fez D. Fr. Timóteo procurar habilitandos ao sacerdócio nas fileiras das companhias, o que desagradou o general Gomes Freire de Andrade. Além disso, o almoxarife da fazenda real, Salvador Dias, conta que foi notificado pelo bispo a "pagar um conto e 500 mil reis sobre pena de excomunhão". Salvador Dias contou que quando o bispo "o vio provido no offício de almoxarife tratou de requerer com instancia diante do provedor da fazenda de vossa majestade a satisfação de sua côngrua". O almoxarife disse não ter ordens de pagar a côngrua e que ainda não estava a par das receitas. O bispo o mandou excomungar "prohibindo as suas ovelhas a communicação dele, em tempo tão necessário ao real serviço de vossa majestade”. Ele não pôde receber as munições e armas vindas do reino por causa daquela excomunhão. O almoxarife foi mandado preso para a cadeia da cidade e a absolvição "foy concedida com pena pecuniária, e penitenciaria” (AHU, Capitania do Maranhão, doc. 1013, fl. 12).

As missivas enviadas ao reino sempre reclamavam que o prelado não aceitava "as cartas rogatórias que do juízo da coroa de vossa majestade lhe tem enviado, mostrandosse independentes a ellas” (AHU, Capitania do Maranhão, doc. 1013, fl. 12v). Mais graves seriam as queixas sobre o desinteresse das pessoas em assumir o cargo de adjunto desse mesmo tribunal por causa das pressões feitas por D. Fr. Timóteo. Segundo a carta, o bispo e seus pregadores usavam os púlpitos contra "qualquer agravo ou determinação do juizo da coroa, e contra os ministros. E na mesma forma se maltratão as pessoas que avexadas recorrem ao dito tribunal, lançando-os das Igrejas fora" (AHU, MA, doc. 1031). Davam conta a vossa majestade

que não será possível daqui por diante verem quem queira servir de adjunto do Juizo da Coroa deste Estado, pellos medos que o bispo mete a todos os que tem servido ha anos a esta parte havendo-os por excomungados, obrigando-os a que se fossem absolver publicamente a matriz, não obstante ser já sobre cazos julgados, e decididos nesse reino contra o ecclesiástico. (Idem)

A historiografia local, como já mencionado, falou pelo bispo ora acusando-o, ora defendendo-o. Mário Meireles afirma que a série de medidas tomadas por D. Fr. Timóteo visaram a normalização do governo diocesano e a moralização dos costumes da comunidade; fê-lo, porém, segundo suas palavras, "de modo tão inconsequente, sem pensar nas circunstâncias, que com 
elas acabaria por provocar a mais lamentável e mesmo vergonhosa crise jamais sofrida pela igreja maranhense" (Meireles, 1977, p. 99). É certo que Meireles carrega nas tintas para tratar das medidas tomadas pelo bispo. O que é evidente, entretanto, é que tais medidas causaram muitos problemas àquela época. D. Fr. Timóteo aconselhava - e em alguns casos, obrigava - que todos os casais denunciados na visita pastoral por crimes de concubinato casassem, inclusive nos casos que envolvessem senhores e suas escravas. Essa "revolta geral" de que também tratam as cartas da câmara, como vimos, era decorrente da tentativa de moralização dos costumes ao modo de Trento, mas não levava em consideração as questões de qualidades desiguais entre os concubinários.

César Augusto Marques também atribui a esse bispo a primeira tentativa de moralização de costumes levada a cabo pela igreja do Maranhão, já que, "mui zeloso e severo em manter no rebanho confiado a seus cuidados a pureza dos costumes, procurou logo acabar com o escândalo e quase geral concubinato, que então aqui havia". E "tendo que lutar com a maior parte da população onde infelizmente se encontravam as pessoas mais qualificadas, levantou contra si grande indisposição" (Marques, 2008, p. 114). D. Francisco de Paula e Silva, por sua vez, afirmou que o bispo "armado com seus poderes que lhe davam as leis então vigentes, procedeu contra os criminosos com todo o rigor; processou-os summariamente, prendeu a uns, metteu a outros na cadeia, obrigou outros a deixarem a vida que levavam". Afirma numa leitura de viés religioso que, "como o vício era quase geral e nelle andavam tanto pessoas qualificadas como gente do povo, não tardou em suscitar contra si o clamor geral”. Defendendo-o como grande pastor de sua ovelhas, D. Francisco afirma que D. Fr. Timóteo não "se abateu nem se amedrontou; antes continuou com mão firme e animo resoluto o seu ministério de reforma dos costumes" (Silva, 1922, p. 83).

O que podia explicar o comportamento do bispo? Em meados do século XVII, os tratados de vertente canônica passaram a se preocupar mais "com a natureza da função e da autoridade episcopal nos seus territórios e com suas obrigações legais" (Paiva, 2006, p. 147). Segundo José Pedro Paiva, "parece que as publicações sobre o episcopado das décadas do meio do século XVII desenvolveram menos a tradição do bispo pastor até então dominante, do que as questões da administração da diocese e as ambições de centralização da cúria romana". Afirma ainda que "como consequência, [...] os tratadistas preocuparam-se principalmente em guiar os bispos no exercício dos seus poderes, especialmente o de jurisdição". Por isso, continua o mesmo autor, "se estes tratados propuseram uma imagem do que devia ser o antístite, ela era a de um homem que sabia governar a diocese e cujas virtudes eram sobretudo 'políti- 
cas'” (Idem, p. 148). D. Fr. Timóteo, teólogo, citou em suas pastorais vários autores e tratadistas do século XVII quando pretendeu defender sua jurisdição episcopal (Apem, Livro de Provisões, n. 81).

Como defende Paiva, o que "importa reter é que a capacidade de governo do bispo e a defesa da sua jurisdição, tornaram-se essenciais na literatura dessa altura" (Paiva, 2006, p. 151), já que, "nos finais de Seiscentos e nos século XVIII, foi adquirindo maior importância o padrão do bispo bom governador e defensor do seu poder jurisdicional na esfera da Igreja" (Idem, p. 152), destacando-se "uma preocupação evidente com a defesa da jurisdição episcopal nos seus territórios e com a afirmação dos bispo como zelador da fé, por via do controlo de pregadores e confessores" (Idem, p. 152-153). D. Fr. Timóteo parece ter sido um bispo político como outros bispos do século XVII. Defendeu e tentou reforçar sua autoridade episcopal desde que chegou ao seu território e, para isso, como vimos, se indipôs com os oficiais do monarca a ponto de ter sido censurado fortemente por eles. Se buscou reforçar sua autoridade episcopal diante dos agentes da coroa, agiu igualmente diante das ordens regulares. E isso examinaremos a seguir.

\section{CONFLITOS COM O CLERO REGULAR}

Em pastoral mandada publicar pelo bispo em 1699 constam mais detalhes dos motivos do conflito com o ouvidor Matheus Dias da Costa, afirmando que a excomunhão "se revalidou e confirmou na corte de Lisboa por junta de theólogos e juristas que sua magestade Deos guarde mandou convocar para este effeito" (Apem, Livro de Provisões, n. 81, fl. 45). O ouvidor já tinha retornado para Belém e as temporalidades tinham sido revogadas. Em fevereiro de 1700 as contendas ainda continuavam. O ouvidor tinha falecido e sido enterrado, ainda sob excomunhão, na igreja do Pará. O alvo das repreensões de D. Fr. Timóteo era as ordens regulares. Os oficiais da câmara comunicaram ao rei que o "prelado intrometece com as religiões do Carmo e Santo Antonio entreditandoas a todo povo e excomungando alguns religiosos della se intrometeo tambem com o comissário da bulla da cruzada impedindoo para a publicação della" (Apem, Copiador de Cartas da Câmara de São Luís, n. 28, fl. 68). O bispo respondeu com a interdição da Igreja e a excomunhão de alguns de seus religiosos.

D. Fr. Timóteo afirma ter mandado fazer sumário de testemunhas no Pará e ter constatado que o ouvidor morreu sem arrepender-se nem pedir absolvição. Assim, os religiosos não o deveriam ter enterrado no convento e igreja 
do Carmo e, por isso, os mandou interditar. Apelaram, segundo o bispo, fazendo duas petições "fora do estilo", o que ele não aceitou. Isso os fez apelar para o juízo da coroa (Apem, Livro de Provisão, n. 81, fl. 45). Antes, porém, os próprios religiosos escreveram para o rei D. Pedro II. Contaram que o bispo

deixou de obedecer a carta de vossa magestade em que lhe encomendada mandasse suspender com as censuras, para que na igreja do Pará dos suplicantes se celebrassem os ofícios divinos, o que fez então o contrario repetindo contra os suplicantes as censuras com o mayor escândalo e dando daquele povo e tudo nacido e originado do odio com que praticara contra hum ministro de vossa magestade lá sepultado que morreu com todos os sacramentos. (AHU, MA, doc. 1021)

O bispo insistiu com as censuras e publicou mais cinco pastorais contra os religiosos. Na primeira, contra os padres capuchos, excomungou seu prior, o comissário do convento em São Luís, e o provincial da ordem do Carmo do Pará. Alegava que os capuchos estavam perturbando "nossa jurisdição ordinária” por recorrerem ao tribunal da coroa (Apem, Livro de Provisões, n. 81, fl. 47). Na pastoral publicada contra os religiosos de Nossa Senhora do Monte do Carmo, o bispo cita a Bula de Clemente VIII do ano de 1604 pela qual os religiosos do Carmo não poderiam recorrer em juízo secular. D. Fr. Timóteo disse que, depois que determinou a excomunhão desses religiosos, eles se armaram para atacar o tesoureiro da sé, pelo que foram excomungados. Os moradores do Maranhão e do Pará foram proibidos de receber ofícios divinos desses religiosos sob pena de excomunhão maior ipso facto incurrenda (Apem, Livro de Provisões, n. 81, fl. 48).

A contenda, como vimos, voltou para o campo do tribunal secular. Embora admoestando o prelado, o rei reconhecia seus direitos de governo e também admoestou as autoridades locais por desrespeito a ele. O impasse parecia sem fim e D. Fr. Timóteo decidiu ir para o reino, onde pretendia resolver seus problemas administrativos pessoalmente com os representantes da coroa. Tentou autorização para pedir dispensa das funções de bispo do Maranhão ao próprio papa, sinal de tentativa de estreitamento das relações com Roma. No despacho do Conselho Ultramarino é possível conhecer que o bispo pedia que lhe pagassem as congruas devidas e também que lhe dessem essa autorização para ir a Roma tratar de sua dispensa, ao que lhe responderam que "as renuncias dos bispos ou as transições de largar os bispados para outros são dificul- 
tissimas e se não devem conceder sem mui considerado exame" (AHU, MA, doc. 1102).

Após ler as razões para pedir dispensa da diocese, considerou que do que "se queixa, e justifica por certidões juntas: e examinando estas com aquela cautella que o mesmo Pontífice manda observar me não parecem suficiente as que o bispo allega", já que "a infirmidade deve ser nacida de velhice e achaques taes que o façam totalmente inhabel do exercício episcopal e esta cautela he do mesmo pontifice e as infirmidades que justifica o bispo não são desta calidade". Além disso, consta no parecer que "nem os bispos por qualquer trabalho ou disgosto devem deixar suas ovelhas" (Idem). D. Fr, Timóteo do Sacramento permaneceu em Portugal de 1700 a 1713, quando faleceu. Jamais voltou ao bispado do Maranhão.

\section{CONSIDERAÇÕES FINAIS}

Como demonstrou Paolo Prodi, "os mecanismos da disciplina da alma, do corpo e da sociedade de que a Igreja dispunha foram um elemento decisivo para a própria afirmação da autoridade do centro político" (Prodi, 1994, p. 173). Assim, a autoridade episcopal foi muito importante para a expansão e a consolidação do poder do monarca no Império Português. Como destacou José Pedro Paiva (2006, p. 183), esses prelados "tinham-se tornado criaturas do rei e este usava-os ao seu serviço, transformando-os, simultaneamente, em servidores da Igreja e agentes políticos da monarquia”. Se, por um lado, eram "criaturas do rei", como defende Paiva, por outro os bispos e, especialmente a figura que aqui destacamos, D. Fr Timóteo do Sacramento, poderiam se contrapor às demais autoridades e oficiais da monarquia com as quais tinham que conviver no ultramar em fins do século XVII.

O bispo do Maranhão pretendeu tomar posse de seu governo diocesano da maneira mais ampla possível, como defendiam as determinações do Concílio de Trento. Implementou medidas para estruturar melhor a malha diocesana e efetuou o provimento de oficiais da justiça eclesiástica no Maranhão e no Pará. Defendeu sua jurisdição e imunidade quando dos inúmeros conflitos com os oficiais seculares e, mesmo recebendo censuras, apelou para o rei e para o papa para defender sua autoridade prelatícia. Era evidente que sua presença e seu posicionamento em defesa da jurisdição episcopal iriam causar conflitos com os que lá governavam, principalmente os oficiais subordinados ao rei. Observamos aqui a oscilação de comportamento do próprio monarca, 
que se alternou ora na defesa do bispo, ora na defesa dos seus oficiais seculares. Eram as muitas adaptações que a igreja sofreria no ultramar.

O bispado tinha apenas duas décadas de existência e a atuação do seu segundo bispo demonstra a tentativa de sua consolidação. Os agentes do juízo da coroa, o governador, o ouvidor e o próprio senado da câmara tiveram que se habituar a mais uma autoridade que com eles rivalizaria em questões as mais diversas. Essa autoridade, entretanto, tinha poderes espirituais e usou a excomunhão quando achou necessário. Esse era um dado novo para aqueles homens habituados a resolver os seus conflitos apenas no âmbito temporal. D. Fr. Timóteo também enfrentou conflitos com clérigos regulares que há tempos eram quase absolutos a governarem as almas naquelas plagas, o que demonstra que em defesa da autoridade episcopal valia até se indispor com outros membros da igreja.

As medidas tomadas por D. Fr. Timóteo do Sacramento são testemunho da busca pela consolidação da jurisdição episcopal num território chave para a monarquia portuguesa em fins do século XVII. Durante a permanência desse bispo na primeira diocese da Amazônia o que se viu foi a busca pelo reordenamento de poderes e pelo alargamento da jurisdição episcopal proposto por Trento. Não poderia ser diferente. Câmara e bispo teriam que (con)viver no mesmo espaço de poder. Governador, ouvidor e as diferentes ordens regulares teriam que se habituar à figura do antístite. Esse cenário conflituoso pode ter se repetido em outras partes e o caso do Maranhão aponta caminhos para se compreender como eram complexos os primeiros anos de uma diocese. Eram a igreja e seus bispos tentando ficar visíveis em variadas partes do Império Português.

\section{REFERÊNCIAS}

ALVES, Ana Maria Mendes Ruas. "O Reyno de Deos e a sua justiça”. Dom Frei Inácio de Santa Teresa (1682-1751). Tese (Doutorado em História) - Faculdade de Letras, Universidade de Coimbra, Coimbra, 2012.

AZEVEDO, João Lúcio de. Os Jesuitas no Grão-Pará: suas missões e a colonização. Belém: Secult, 1999.

BERREDO, Bernardo Pereira de. Anais históricos do Estado do Maranhão em que se dá notícia do seu descobrimento. 4. ed. São Luís: Alumar, 1988.

BETTENDORF, João Felipe. Cronica da missão dos padres da Companhia de Jesus no estado do Maranhão. Belém: Fundação Cultural Tancredo Neves: Secult, 1990.

BOXER, Charles. A Igreja e a expansão ibérica (1400-1770). Lisboa: Edições 70, 1978. 
CAETANO, Antonio Filipe Pereira. Entre drogas e cachaça: a politica colonial e as tensões na América Portuguesa (Capitania do Rio de Janeiro e estado do Maranhão e Grão-Pará, 1640-1710). Tese (Doutorado em História) - Universidade Federal de Pernambuco, Recife, 2008.

CARDOSO, Alirio. Maranhão na Monarquia Hispânica: intercâmbios, guerra e navegação nas fronteiras das Índias de Castela (1580-1655). Tese (Doutorado em História) - Universidade de Salamanca, Salamanca, 2012.

CARVALHO JÚNIOR, Almir Diniz. A ordem da missão e os jogos da ação: conflitos, estratégias e armadilhas na Amazônia do século XVII. Revista Tempo, v. 19 n. 35, p. 23-41, 2013.

CHAMBOULEYRON, Rafael. Escravos do Atlântico equatorial: tráfico negreiro para o Estado do Maranhão e Pará (século XVII e início do século XVIII). Revista Brasileira de História, v. 26, p. 79-114, 2006.

CORREA, Helidacy Muniz. Para o aumento da Conquista e bom governo dos moradores: o papel da Câmara de São Luís na Conquista, defesa e organização do território do Maranhão (1615-1668). Tese (Doutorado em História Social) - Universidade Federal Fluminense, Niterói, 2011.

FERREIRA, André Luís Bezerra. Nas malhas das liberdades: o Tribunal da Junta das Missões e o governo dos índios na Capitania do Maranhão (1720-1757). Dissertação (Mestrado em História Social) - Instituto de Filosofia e Ciências Humanas, Universidade Federal do Pará, Belém, 2017.

LARCHER, Madalena. SACRAMENTO, D. Fr. Timóteo do (1653-1713). In: Enciclopédia virtual da expansão portuguesa. Lisboa: Universidade de Lisboa, 2009.

LIBERMAN, Maria. O levante do Maranhão, “judeu cabeça do motim”: Manoel Beckman. São Paulo: FFLCH/USP: Centro de Estudos Judaicos, 1983.

MUNIZ, Pollyanna. Réus de Batina: Justiça Eclesiástica e clero secular no Maranhão colonial. São Paulo: Alameda-Edufma, 2017.

MARQUES, Cezar Augusto. Dicionário histórico-geográfico da província do Maranhão: notas apuração textual de Jomar Moraes. São Luís: Edições AML, 2008.

PACHECO, Felipe Condurú. História eclesiástica do Maranhão. São Luís: Departamento de Cultura, 1969.

PACHECO, D. Felipe Conduru. Relações entre o poder civil e o poder eclesiástico no Estado do Maranhão durante o século XVII. Revista do IHGB, Rio de Janeiro, v. 308, 1975.

PAIVA, José Pedro. Os Bispos de Portugal e do Império (1495-1777). Coimbra: Imprensa da Universidade de Coimbra, 2006.

PAIVA, José Pedro. Reforma religiosa, conflito, mudança política e cisão: o governo da diocese de Olinda (Pernambuco) por D. Fr. Luís de Santa Teresa (1738-1754). Revista de História da Sociedade e da cultura, Coimbra, n. 8, p. 161-210, 2008. 
PAIVA, José Pedro. Uma religião para o mundo: padroado régio e uma diocese pluricontinental. In: PAIVA, José Pedro; FIOLHAIS, Carlos; FRANCO, José Eduardo (org.). História Global de Portugal. Lisboa: Círculo de Leitores, p. 353-359, 2020.

PRAZERES, Frei Francisco de Nossa Senhora dos. Poranduba maranhense, ou Relação historica da provincia do Maranhão com um dicionario abreviado da lingua geral do Brazil. Revista Trimensal do Instituto Historico e Geographico Brazileiro, v. 54, p. 4-277, 1891.

PRODI, Paolo. Disciplina dell'anima, del corpo e disciplina della società tra medievo ed etá moderna. Bologna: Society Editrice il Mulino, 1994.

REIS, Arthur Cezar Ferreira. A Conquista Espiritual da Amazonia. Manaus: Edua: Governo do Estado do Amazonas, 1997.

SANTOS, Gustavo Mendonça dos. A justiça do bispo: o exercício da justiça eclesiástica no bispado de Pernambuco no século XVII. Tese (Doutorado) - Universidade Federal de Pernambuco, Recife, 2019.

SILVA, Dom Francisco de Paula e. Apontamentos para a História eclesiástica do Maranhão. Bahia: Tipografia de São Francisco, 1922.

XIMENDES, Carlos Alberto. Sob a mira da Câmara: viver e trabalhar na cidade de São Luís (1644-1692). Tese (Doutorado em História) - Instituto de Ciências Humanas e Filosofia, Universidade Federal Fluminense, Niterói, 2010.

SOUZA, Evergton Sales. A construção de uma cristandade tridentina na América portuguesa. In: GOUVEIA, António Camões; BARBOSA, David Sampaio; PAIVA, José Pedro (org.). O Concílio de Trento em Portugal e nas suas conquistas: novos olhares. Lisboa: CEHR/Universidade Católica Portuguesa, p. 175-195, 2014.

\section{Notas}

${ }^{1}$ Este artigo é uma produção do projeto Religião, Administração Eclesiástica e Justiça no Império Português (1514-1750) - ReligionAJE, PTDC/HAR-HIS/28719/2017, patrocinado pela Fundação Portuguesa de Ciência e Tecnologia e H2020, e conta ainda com financiamento concedido pela Fundação de Amparo à Pesquisa Ciência e Tecnologia do Estado do Maranhão através de dois projetos: Universal-01310/18 e Bolsa de Pós-Doutoramento (BPD-90866/2018).

${ }^{2}$ Antes dele, D. Fr. Gregório dos Anjos, o primeiro bispo, esteve na região de 1679 a 1689, quando faleceu (Muniz, 2017, p. 22).

${ }^{3}$ Segundo José Pedro Paiva, o padroado consistia num conjunto de direitos (honoríficos, de apresentação às autoridades eclesiásticas dos servidores das igrejas e de cobrança de rendas) e de encargos (construir e defender igrejas, provê-las de objetos de culto, assegurar a sua sustentação e a dos clérigos) que a Igreja atribuía, como recompensa pelos serviços 
prestados, aos fundadores, construtores e dotadores de igrejas ou de benefícios eclesiásticos (Paiva e Fiolhais, 2020, p. 354).

${ }^{4}$ Trata-se do livro de provisões número 81, completamente inédito e restaurado pelo Arquivo Público do Maranhão. Esse é provavelmente o livro da chancelaria, pois não contém apenas as provisões.

${ }^{5}$ Timóteo do Sacramento was born in Lisbon on February 5, 1653. He professed in the Hermits of Saint Paul Order, of the Congregation of Serra d'Ossa, in the Convent of the Holy Sacrament in that city, on July 14, 1670. Confirmed as bishop of São Tomé and Príncipe on January 2, 1693, he would be appointed bishop of Maranhão by King Pedro in 1695, an appointment that was confirmed by the papal bull of Innocent XII, Gratiae divinum praemium, dated December 17, 1696. He would arrive in São Luís on June 13, 1697. LARCHER, Maria Madalena Pessố Jorge Oudinot. LARCHER, Madalena. SACRAMENTO, D. Fr. Timóteo do (1653-1713). In: Enciclopédia virtual da expansão portuguesa. Lisboa: Universidade de Lisboa, 2009.

${ }^{6}$ Movimento revoltoso ocorrido entre 1684-1685 em decorrência, entre outras coisas, da experiência fracassada da Companhia de Comércio do Maranhão, de 1682, que fora instituída para introduzir mais regularmente os escravos africanos ao Estado, devido a uma lei de liberdade indígena publicada em 1680. A historiografia comenta que o bispo D. Fr. Timóteo hospedou-se na casa das viúvas dos insurretos, os irmãos Manuel e Tomás Beckman, assim que chegou ao bispado (Silva, 1922); (Meireles, 1974).

${ }^{7}$ Para saber mais sobre as funções e competências desses oficiais, consultar: Regimento do Auditório Ecclesiástico do Arcebispado da Bahia, Metropoli do Brasil. São Paulo: Typographia 2 de Dezembro, 1834, Tit II, $₫$ I, fl. 16; n 62, fl. 19 e n 63, fl. 19; tit XVII, n.530, fl. 114, respectivamente.

${ }^{8}$ A historiadora portuguesa Maria Madalena Larcher apresenta ano da morte do bispo diferente do que está informado pela historiografia brasileira. Mario Meireles (1977), D. Francisco de Paula (1922) e D. Felipe Pacheco (1969) afirmam que o ano da morte foi 1714, mas o trabalho de Larcher conclui que "Friar Timóteo do Sacramento died on December 9, 1713, at the age of 60. His tombstone contains the epitaph: "Here lies the Illustrious Friar Themoteo do Sacramento, Bishop of Maranhão, who died on Dec. 9 of the year 1713".

${ }^{9}$ Há mais detalhes desses acontecimentos em vários documentos do Desembargo do Paço na Torre do Tombo. IANTT, Desembargo do Paço, Repartição das Justiças e Despachos da Mesa, Maço 937 (1700-1752). 